\title{
Biomimetics and Sustainability
}

\author{
Sheelratan S. Bansode, Pritish G. Chitte, Sachin S. Rathod, G. R. Hiremath, Ravi Teja, Rakesh \\ Yadav
}

\begin{abstract}
Since years human always try to look into nature for better solutions, thus there are lot many examples where nature inspired solutions for the engineering and other problems have proved to be a benchmark. The techniques or the solutions from the nature are well tried and tested as natural systems are designed by nature to the best and at the optimized level. As it is well known that the nature do not generate any kind of waste, nor does it consumes large amount of resources to develop its own systems. Thus the solution obtained from the surroundings can prove to be the optimized solutions in a sustainable manner.
\end{abstract}

Keywords:

-biomimetics,

biomimicry,

optimisation, sustainability.

\section{INTRODUCTION}

Many studies can be found where the excellence of nature and its engineering is mention and the strong desire of the researchers to use these engineered systems into technology. Biomimetics is an important aspect for motivating the advances as long as technical advances are accounted. The problems from the world can easily be taken into account by it. The large potential of it is the main feature for its increasing investigation. The word biomimicry is made of two words, one is bios which means life and the other mimesis which means to imitate. By getting the meaning of the word the concept can be understood easily (http://www.asknature.org/article/view/what_is_biomimicry, 2011). The results obtained from biomimetics are sustainable, perform well, energy saving, reduce material costs, reduce waste thus people have an optimistic look towards biomimetics. But the studies carriedout till date on application of biomimetics are more concerned to product development. On the contrary there are some laws which are common in nature which can be applied to living, social and organizational systems which can be explored. To cash the benefits of these laws, the study of nature's principles for their application to organizations is necessary.

Phil Richardson (2010) in his thesis named this as "Business Biomimetics" and proposed it as the emerging field within biomimetics that demonstrates a strategic use of biomimetics in the business environment. It can be used to develop and optimize processes, for business management,

Revised Manuscript Received on September 10, 2019.

Sheelratan S. Bansode, Walchand Institute of Technology, Solapur, Maharashtra, India.

PritishChitte, Walchand Institute of Technology, Solapur, Maharashtra, India.

Sachin S. Rathod, Walchand Institute of Technology, Solapur, Maharashtra, India.

G. R. Hiremath, Assistant Professor, NBNSCOE, Solapur, Maharashtra, India.

Ravi Teja, Research Scholar, SIU Pune, Maharashtra, India.

Rakesh Yadav, Faculty, SCMHRD, SIU Pune, Maharashtra, India scheduling etc. The concepts behind the use of biomimetics for management practices/techniques are the social animals/species like ants, honeybees, bats, birds, fish etc and their behavior in particular situations. This idea is to merge biology with engineering, to serve humanity take better care of Nature with harmony, hence from an individual to the biggest firm, can generate improved products, get greener to work in agreement with nature.

\section{NEED OF BIOMIMETICS}

The researchers mentions that the prime function of the house is to deliver comfort and safe environment to the living individual as the house is similar to a machine. As per Williamson et al., (2003) now a day's however the thinking process as well as perspective is changing the major concern now is to protect the environment form humans. The buildings functions currently are not only to protect the humans from the environment but also to preserve the external environment. As the living organisms are the best examples who show this kind of behavior. The organism's behavior or the structure often leads to the solution for the problem. There is need for the researchers to look into the environment to develop structures which provide the necessary function to the humans but also at the same time do not harm the environment.

\section{BIOMIMICRY FOR SUSTAINABILITY}

It is well known that the organisms found in the nature are capable of carrying out all the processes without the rigorous use of the fuels, pollution and disturbing the future which the humans desire to do. Sustainability is nothing but carrying out the function in such a way that the upcoming generation can function in the similar manner. When looked into the nature deeply it can be observed that each and every organism is interconnected without wasting anything but recycling and reusing like the waste of one organism is the intake of the other. If the researchers try to mimic nature they may gain the knowledge of how to create structures that can be easily adopted in the natural world as humans do where the given waste is recycled so that the resources can be used in future. In the book by Benyus, (2002) proposes nine criteria's with the help of which the testing of the design can be carried out to check how well it achieve the nature mimicry. The use of primary energy source, optimum energy usage, fitting the shape of the building, handling of the waste, connection with the surrounding environment, diversity, utilization of local resources, optimum utilization

Blue Eyes Intelligence Engineering

\& Sciences Publication

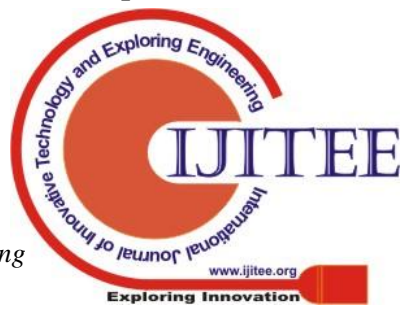


of resources, functioning without the additional devices. These criteria's help to mimic nature to design a good structure and to evaluate whether the design is sustainable or there are some modifications needed

There are various approaches available to get the biological ideas into technology. According to the Zari (2007) there are two approaches under which the biomimetics can be classified.

\section{a. The direct approach}

This direct method of investigation contains several steps illustrated in figure 2, starting by scoping, where the designer defines the design problems and the context of its creation and use. After understanding the problem and design requirements, it is time for idea-generation through retrieving inspiration and engineering solutions from nature. When searching the natural world for examples, it is useful to investigate an array of divergent organisms that rely on different approaches to solve similar problems. This will help us to see which has the best / most relevant strategy and yield a greater variety of ideas with which we develop. The final stage is engineering and evaluation by translating the best strategy to a buildable thing, putting guidelines criteria for product engineering and reaching the optimum solution for the design problem (Panchuk, 2006).

\section{b. The indirect approach.}

It begins with a biological solution that is defined, understood, reframed and then found problems to which the principle could be applied

But it can be mentioned that there are few more approaches like the BioTriz, and the newly developed BIOMIM-TRIZ.

\section{BIO-MIM-TRIZ}

The BIO-MIM-TRIZ design process is based on nature with its infinite variety of shapes, colors and species where the only imperative for living in harmony with nature is mutual respect. Architects enjoy many biological forms, are impressed by their abilities, and are inspired and stimulated by their designs, patterns and structures, then it is logical to see what biology has to offer in terms of design for the engineering purposes of humanity. Living organisms provide inspiration for innovations in many different fields and for entirely different reasons. Therefore the BIO-MIMTRIZ process will implement the usage of biology in architecture. This new Bio-MIM-TRIZ process observes nature to find solutions, not based on contradiction and also helps architects to use nature without a help of biologist is needed. So that it will contain tables that carries all problems faced in nature and their resolutions in biology the development of biological and Bio-TRIZ design processes and will lead to BIO-MIMIZ buildings that achieve goals, principles and features explained in the following section.

\section{APPROACHES TO BIOMIMICRY \& RESULTS} ranked by level of complexity. This design process is due to

\section{EXAMPLES OF BIOMIMETICS IN ARCHITECTURE.}

There are many examples where the biomimetics have solved the human problems. To name some are as follows

a. Lotus plant leaves are water resistance and self cleaning. This is used to develop paints that have the microstructure similar to the lotus leaves which is used to paint the building and the structure is cleaned during rainfall.

b. Mussels form byssal threads underwater this can be utilized to develop adhesives i.e. the plywood glue with the help of soy proteins and this outperforms the regular glues available in the market.

c. Desert plant cactus, use its spines to save energy in form of water. By using this the buildings can be designed to have fins, wind breakers, grills to control the air speed and to provide the thermal comfort.

d. Water lilyfloats on water; the spotlight to floating building. This $\mathrm{cn}$ be used to develop the light weight and floating buildings.

e. The termite mound. This is the practical example that has been implemented to design the Eastgate Building in Zimbabwe. This building is developed on the basis how the termites control the temperature inside their mound irrespective of the surrounding conditions. The air in the mound enter at the base and is directed through the tunnels during this the air gains the temperature and rises up and escapes. The place of hot air is taken by the cold air at the bottom again. It was found that the building uses less energy as compared to any other conventional building of the same size

\section{CONCLUSION}

The architecture and the biology are not different they are wound together by similar systems. When nature has a problem, evolution weeds out what doesn't work and selects the most effective adaptations (Pawlyn, M, 2016). Humans could also address environmental problems by using biomimicry examining nature's solutions and applying them to human designs. Nature has already solved many of the mechanical and structural problems humans face today without generating residual and inactive waste. Biomimetics seeks to remedy such error designing systems. For architectural design to be sustainable, architects are meant to look into the activities, reactions and adaptability of living things in the environment copy and replicate their behavioral or functional life style.

\section{REFERENCES}

1. The Biomimicry Institute. What Is Biomimicry? Ask Nature. [Online] 2008-2011. [Cited: March 10, 2011.] http://www.asknature.org/article/view/what_is_biomimic ry.

2. Phil Richardson, Fitness for the future: applying biomimetics to business strategy, A thesis submitted for the degree of Doctor of Philosophy, University of Bath, 
Department of Mechanical Engineering March 2010

3. Benyus, Janine M. Innovation inspired by nature. Tropicaldesign.org. [Online] 2006. [Cited: March 11, 2011.]

http://tropicaldesign.org/biomimicry/tnep_biomimicry_0 00.pdf.

4. Biomimicry Institute. Toxics. Biomimicry Institute. [Online] 2007-2011. [Cited: March 22, 2011.] http://www.biomimicryinstitute.org/case-studies/casestudies/toxics.html.

5. Biomimicry Institute. Energy. Biomimicry Institute. [Online] 2007-2011. [Cited: March 22, 2011.] http://www.biomimicryinstitute.org/case-studies/casestudies/energy.html.

6. Architecture. Biomimicry Institute. [Online] 2007-2011. [Cited: March 22, 2011.] http://www.biomimicryinstitute.org/case-studies/casestudies/architecture.html.

7. Beijing Municipal Planning Commission. "Announcement for the International Architecture Scheme Competition for the Conceptual Design of the National Stadium in Beijing." Beijing Global Strategy Consulting Co. Inc. 16 December 2002. 9 December 2006.

8. 〈http://www.strategy4china.com/designstadium.pdf>

9. http://www.ibef.org/industry/indian-textiles-and-apparelindustry-analysispresentation, Textiles and Apparel, India Brand Equity Foundation (IBEF)-June 2017

10. Benyus, J. M (2002). Biomimicry: Innovation Inspired by Nature. Perennial, New York

11. Zari, M. P., (2007). Biomimetic Approaches to Architectural Design for Increased Sustainability. InSB07. New Zealand, 14 November 2007. Wellington, New Zealand: School of Architecture, Victoria University. 1- 10.

12. Panchuk, N. (2006). An Exploration into Biomimicry and its application in Digital \& Parametric [Architectural] Design. Thesis (Master degree). University of Waterloo

13. Pakinam Barakat, Ali Bakr, ZeyadElsayad, (2016)Towards A New Biomimic Approach, New BioMim-Triz Design Process, Proceedings of 34th IASTEM International Conference, London, United Kingdom.

\section{AUTHORS PROFILE}

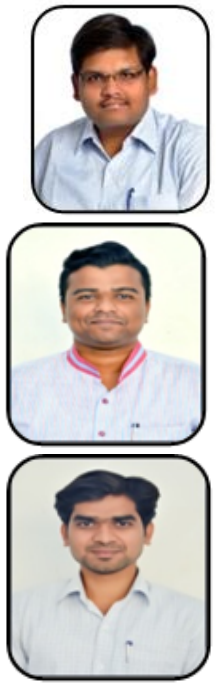

Sheelratan S. Bansode,

B. E. (Mechanical), M. E. (Mechanical Design), Ph. D. Scholar, Walchand Institute of Technology, Solapur.

Email-id: bansodesheel@ rediffmail.

Mr. P. G. Chitte

B. E. (Mechanical), M. Tech. (Mechanical), Assistant Professor, Mechanical Engineering Department, Walchand Institute of technology, Solapur.

Email id: pritish0203@gmail.com

Mr. S. S. Rathod

B. E. (Mechanical), M. Tech. (Mechanical) Assistant Professor, Mechanical Engineering Department, Walchand Institute of technology, Solapur.

Email id:sachin.rathod4@gmail.com
Mrs. G. R. Hiremath

B. E. (E\&TC), M. E. (Electronics), Assistant Professor, NBNSCOE, Solapur.

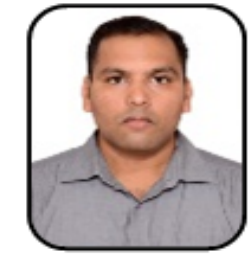

\section{Mr. Ravi Teja}

M. Tech (Chemical Engineering), Research Scholar, SCMHRD, Pune

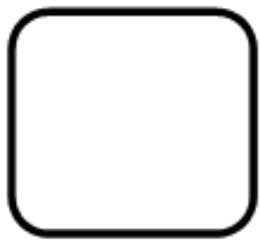

Dr. Rakesh Yadav

Post
PhD(Mumbai),

doc(Latvia),PhD(TISS)

Faculty SCMHRD, Pune. 